\title{
The impact of Theraplay® therapy on parent-child interaction and child psychiatric symptoms : a pilot study
}

\section{Salo, Saara}

2020

Salo , S , Flykt , M , Mäkelä , J , Lassenius-Panula , L , Korja , R , Lindaman , S \& Punamäki , R-L 2020 , ' The impact of Theraplay ${ }^{\circledR}$ therapy on parent-child interaction and child psychiatric symptoms : a pilot study ' , International journal of play , vol. 9 , no. 3 , pp. 331-352 . https://doi.org/10.1080/21594937.2020.1806500

http://hdl.handle.net/10138/340972

https://doi.org/10.1080/21594937.2020.1806500

cc_by_nc

acceptedVersion

Downloaded from Helda, University of Helsinki institutional repository.

This is an electronic reprint of the original article.

This reprint may differ from the original in pagination and typographic detail.

Please cite the original version. 
The impact of Theraplay ${ }^{\circledR}$ therapy on parent-child interaction and child psychiatric symptoms: A pilot study

Saara Salo

Saara.z.salo@helsinki.fi

Helsinki University

Marjo Flykt

Tampere University

Marjo.flykt@uta.fi

Jukka Mäkelä

National Institute for Health and Wellfare

Jukka.makela@thl.fi

Lotta Lassenius-Panula

lotta.lasseniuspanula@gmail.com

Riikka Korja

Turku University

riipen@utu.fi

Sandra Lindaman

The Theraplay Institute, Evanston, IL

slindaman@att.net

Raija-Leena Punamäki-Gitai

Tampere University

raija-leena.punamaki-gitai@tuni.fi 


\begin{abstract}
Childhood emotional and behavioral psychiatric problems are a serious developmental risk for long-term psychiatric disorders. The quality of the early parent-child relationship is the most crucial factor for healthy socio-emotional development. Theraplay® is a parent-child interaction therapy combining structured, attachment-based, joyful and adult-led playful sessions with reflective guidance work with the parents. This pilot study evaluates the impact of Theraplay® therapy in improving the quality of parent-child interaction and decreasing the internalizing and externalizing symptoms of children diagnosed with emotional and/or behavioral disorders within a clinical child psychiatric outpatient setting. Participants were eighteen $4-8$ year-old children $(M=4.42, S D=1.54)$ from two outpatient child psychiatric clinics whose mothers, and in 13 of those cases fathers also participated in the Theraplay® therapy together with the child. Pre- and post-treatment measures included videotaped observations of parent-child interaction quality, and child psychiatric symptoms (CBCL). The results showed improvements in parent-child interaction quality as well as decreases in children's internalizing and externalizing symptoms. The results of this pilot study indicate that Theraplay® therapy may be a useful treatment among children diagnosed with emotional and/or behavioral psychiatric disorders.
\end{abstract}

Keywords: Parent-child interaction, Theraplay® therapy, internalizing symptoms, externalizing symptoms, parent-child interaction, child psychiatry

Corresponding author: saara.z.salo@helsinki.fi 



\section{Introduction}

Children's emotional and behavioral difficulties cause deep worry in parents and can severely interfere with parent-child interaction. On the other hand, parenting problems may lead to the development of child's psychiatric symptoms. A meta-analysis on the estimated worldwide prevalence rate for childhood psychiatric diagnoses has been 13.4\% (Polanczyk, Salum, Sugay, Caye, \& Rohde, 2015). As rates of psychiatric diagnoses in childhood have increased, a growing number of young children are now requiring psychotherapeutic treatments and a variety of other educational and other special interventions (Atladottir et al., 2014; Olfson, Blanco, Wang, Laje, \& Correll, 2014).

Furthermore, in addition to reducing psychiatric symptoms, improving resilience through positive qualities in parent-child interaction may be especially relevant for improving intervention efficacy. Consequently, we need more information about structured therapies that could be effective for children with psychiatric emotional and behavioral diagnoses and their families. The aim of this study is, first, to introduce Theraplay®, a short-term playful parent-child interaction therapy as an integrative treatment model focusing especially on the positive, playful aspects of parent-child relations. Second, this study pilots the effectiveness of Theraplay® in improving the dyadic parent-child interaction quality and decreasing children's internalizing and externalizing psychiatric symptoms in childpsychiatric outpatient setting.

\section{Childood emotional and behavioral problems and positive parent-child interaction}

Central to Belsky's (1997a, 1997b, 2005) evolutionary-inspired differential susceptibility hypothesis is the proposition that vulnerable children are especially sensitive to their early interaction experiences with their parents. It thus suggests that children suffering from psychiatric levels of internalizing or externalizing problems would benefit greatly from optimal social interaction. As highlighted by two major theoretical and empirical traditions, social-learning theory focusing on adequate guidance and rearing practices and attachment-theory on the emotional components of parentchild relations, both sides of parent-child interaction need to be considered (e.g., Sanders \& Turner, 2018).

Consequently, first, as outlined by social-learning theorists, parental guidance skills include structuring the child's behavior and emotion regulation, teaching the child new skills as well as setting developmentally appropriate challenges and limits (Keenan \& Shaw, 1995; Maccoby, 2015; Patterson, 2002). Review studies have shown that both parental harsh control and permissive and neglectful rearing style, i.e., both over- and undestructuring, systematically predict higher levels of 
children's externalizing and internalizing problems, such as conduct disorder and depression (Pinquart, 2017; Yap \& Jorm, 2015).

Secondly, emotional concepts derived from attachment theory have been related to optimal child development and lower levels of psychiatric problems. For example, harmonious and reciprocal interaction at preschool age predicted low rates of internalizing symptoms in middle childhood, whereas conflicting and indifferent interactions predict high symptom rates (DuboisComtois, Moss, Cyr, \& Pascuzzo, 2013). Maternal sensitivity, referring to emotionally contingent responding to child's cues, has also been been shown to predict fewer internalizing (Kok et al., 2013) as well as externalizing problems, with a decrease in maternal sensitivity from ages 3 to 11 being related to a systematic increase in externalizing behavior from ages 4 to 12 (Wang, Christ, MillsKoonce, Garrett-Peters, \& Cox, 2013). In a similar vein, nurturing behaviors, including the use of regulative physical touch, may be especially important in promoting children's later emotional and behavioral outcomes (Feldman, 2012), and increasing them has been found effective in enhancing emotion regulation for example among children with ADHD (Field, 2014; Siu, 2017) and with developmental disabilities (Stevens \& Holcombe, 2015). Some research is also available on the unique role of shared dyadic positive affects, "moments of joy" in contributiong to optimal child development (Feldman, 2003; Fogel, 1993). Cross-sectional research shows that positive affect in parent-child interactions is associated with children's lower levels of behavior problems in early childhood (e.g., Deater-Deckard, Atzaba-Poria, \& Pike, 2004; Harrist, Pettit, Dodge, \& Bates, 1994). Similarly, longitudinal research indicates that shared pleasure in early infancy predicts fewer internalizing and externalizing problems at two years (Mäntymaa et al., 2015), and positive affect predicts lower levels of externalizing problems from three to age five and a half years both for mothers and fathers (Lunkenheimer et al., 2011). Similary, mothers' contingent, positive responses predict reductions in children's externalizing problems from age five to age seven (Cole, Teti., \& Zanh-Waxler, 2003).

Taken together, both parental overall guiding and rearing practices as well as emotional capabilities such as sensitivity, nurture and positive affects are important to support adaptive socioemotional development especially among children experiencing high levels of emotional and/or behvioral disorders.

\section{Parenting interventions targeting early childhood emotional and behavioral problems}

Reflecting the separate traditions of social learning and attachment theories, parenting intervention studies have often focused on either improving parental rearing skills or emotional 
capacities underlying attachment. There is already substantial evidence that structured parenting interventions based on social learning theories and focusing on teaching parental guidance skills, such as limit-setting practices, reduce child externalizing problems such as conduct problems (see Gardner, Montgomery, \& Knerr, 2015; Tully \& Hunt, 2015) as well as child internalizing depressive and anxiety problems (Yap et al., 2016). The results appear robust regardless of the format of the intervention, as they have comprised a wide array of approaches, such as short-term educational parental guidance, parenting schools, and their combinations (Gardner et al., 2015). While many of these parental guidance-based interventions are offered to parents only, without the presence of their children, and focus on non-clinical levels of emotional and behavioral symptoms, there are also relational interventions. For example, widely used parent-child interaction therapy (PCIT; Eyberg, Nelson, Duke, \& Boggs, 2008) has focused on directly teaching the parents how to respond to child misbehavior through a variety of play therapy skills with strong positive results in a variety of clinical settings (Quetsch, Wallace, Norman, Travers, \& McNeil, 2015). Specifically in relation to child mental health problems, Pearl and colleagues (2012) examined the effectiveness of PCIT with high-risk families receiving services from community agencies and found that children in this sample experienced significant reductions in internalizing and externalizing problems, disruptive behavioral problems, and trauma symptoms after PCIT. Focusing interventive efforts on parental guiding skills using play as an avenue for change seems, consequently, to have generally beneficial effects even for children with clinically high levels of emotional and behavioral problems.

Attachment-based interventions represent another type of evidence-based approach to increase emotional relational quality and to decrease child emotional and/or behavioral symptomology (Bakermans-Kranenburg, Van Ijzendoorn, \& Juffer, 2003; Mountain, Cahill, \& Thorpe, 2017; Zeanah, Berlin, \& Boris, 2011). Most effective programs have been relatively brief and utilized video feedback, and their main focus has been on increasing the overall parental sensitivity, i.e., their capacity for reading and responding to children's needs and emotional cues (Bakermans-Kranenburg et al., 2003). For example, videofeedback intervention to promote positive parenting and sensitive disciple (VIPPSD), a short-term intervention utilizing psychoeducation about attachment by positive video-feedback from parent-child interactions, has been shown to be successful in reducing behavior problems in children (Juffer, Bakermans-Kranenburg, \& van Ijzendoorn, 2017). The Circle of Security (COS; Powell, Cooper, Hoffman, \& Marvin, 2014) intervention, which focuses in improving parental understanding of the importance of attachment relations, has been shown to have significant effects in 
reducing child externalizing as well as internalizing symptomology. The study included children ranging in age from one to seven years, (Huber, McMahon, \& Sweller, 2015). However, many attachment-based interventions have focused only on the early years, and/or they have not included psychiatrically referred clinical populations. Finally, it has been recently emphasized that in order to change parental sensitivity behaviors, it may be significant to change the way parents think and understand their children's problem behavior per se. Parents are most likely to respond in sensitive and nurturing ways when they can mentalize their children correctly, i.e., when they understand the meaning and intention underlying the children's behavioral signals (Fonagy, Steele, Steele, Moran \& Higgitt, 1991; Slade, 2005). A recent review on intervention studies focusing on parental mentalization showed improvements in parental sensitivity, and, relatedly, children's' socioemotional well being (Camoirano, 2017). However, most mentalization-based parenting intervention studies to date have focused only on early infancy and childhood (e.g., Pajulo, Suchman, Kalland \& Mayes, 2006; Pajulo et al., 2012; Suchman et al., 2010a,b, 2017).

Taken together, with children experiencing clinically high levels of emotional and behavioral problems, it is vital to use multi-theoretical and multi-method treatment approaches, integrating elements from both social-learning and attachment traditions, and utilizing both direct work with parents and children, parent reflective work, and video feedback. Interventions also need to be applicable for children of varying ages. Finally, research is lacking on interventions that directly increase mutually shared positive affects in parent-child relationships although these may be especially crucial for optimal development especially in high-risk contexts (Lunkenhemer et al., 2011; Mäntymaa et al, 2015).

\section{Theraplay® therapy}

Theraplay ${ }^{\circledR}$ therapy was developed in the late 60 's to aid socially disadvantaged and emotionally disturbed children in the preschool Head Start Program in Chicago. Since then, the Theraplay Institute (TTI) has provided services, developed and trained Theraplay® for children and their families from infancy into adolescence. Theraplay ${ }^{\circledR}$ is practiced internationally in over 30 countries. Theraplay ${ }^{\circledR}$ is child and family therapy for building and enhancing attachment, selfesteem, trust in others, and joyful engagement. It involves the key intervention elements suggested above that relate to both social learning and attachment theories: parental guidance including both 
structure and developmentally appropriate, mastery promoting challenge, as well as sensitivity, termed here as engagement, and nurture (Booth \& Jernberg, 2009). As compared to other parentchild relational treatment models, the unique characteristic of Theraplay® is the use of experiental, structured, and physically active (up- or downregulating) non-symbolic play activities including the use of physical touch. In practice, Theraplay® is a short-term, playful intervention usually lasting about 15 sessions that utilizes attachment-based, adult-led playful activities, videofeedback and direct as well as reflective parent guidance.

Theraplay® focuses first, on helping parents provide appropriate guidance and limitsetting for their child. This is done by creating adult-led, yet fully reciprocal and child initiative promoting therapy sessions. Two therapists are used whenever possible. Thus, parents first observe with their own therapist how the other therapist leads the session with the child, then join in the activities, and eventually take more responsibility in structuring the sessions. At the end of treatment parents lead the challenging, age-appropriate, playful activities by themselves. Discussions about the developmentally appropriate ways of leading the child also take place in separate reflective parental sessions as described below. Second, Theraplay® is unique in that it incorporates play as a central avenue for emotional change. All activities within a session are designed to be playful, focusing on creating engaging, special, and fun moments-of-meeting in parent-child interaction including physical contact, mirroring of affects and joyfulness. Using special play activities gives the parent and the child new possibilities for emotional sensitivity and responsivity that are typical in all attachment-based interventions (Steele \& Steele, 2017). The child's nonverbal messages of uncertainty or concern are empathetically verbalized and parents are encouraged to modify their activity accordingly. Thirdly, in Theraplay®, nurturing is encouraged throughout the sessions in guiding the parents to use gentle physical touch when attending to, caring for and comforting the child. For instance, the therapist helps the parents find ways of calming an over-active or restless child by helping the child accept soothing physical closeness and touch. Fourth, in Theraplay®, special attention is given to help parents gain more reflective and empathetic understanding of the child. Thus, in addition to direct guidance in the sessions, reflective parental work using video-feedback is utilized throughout the process with the direct goal of developing a more reflective stance toward their child. Finally, the parents' own attachment history and trauma experiences are taken into account when planning each intervention. All parents are interviewed pre-intervention with a modified semi-structured interview regarding these 
topics to give the therapists sufficient understanding what difficulties the parent may have in terms of adequate rearing practices, or emotional sensitivity.

An intervention study with pre-post design by Wettig and colleagues (Wettig, Coleman \& Geider, 2011) involved over 200 children receiving Theraplay®. The results showed a significant positive impact on shy children, with a reduction in post-treatment internalizing symptoms. In a similar vein, a randomized control study of 46 children showed that Theraplay® was effective in reducing internalizing symptoms (Siu, 2009). In another study, Theraplay® conducted in a group setting was shown to improve social skills of developmentally disabled children as compared to controls (Siu, 2014, 2017). More recently, a study on 20 children in foster care showed improvements in social skills and reduction in symptoms scores in a pre- and post-design in a school-setting (Francis, Bennion, \& Humrich, 2017). Talen (2000) found Theraplay® activities contributing positively as a part of interventions aimed for children with the physical and behavioral health problems in primary health care context. However, there have not yet been studies involving children with more severe psychiatric symptomology. As children experiencing more severe internalizing and externalizing symptoms occurring often simultaneously (Patalay, Moulton, Goodman, \& Ploubidis, 2017) may be more difficult to treat a study of the feasibility and impact of Theraplay® in clinical child psychiatric setting is clearly needed.

\section{Study aims and hypotheses}

Our aim is to evaluate the effectiveness of Theraplay ${ }^{\circledR}$ therapy in improving the quality of parent-child interaction and in reducing children's internalizing and externaling symptoms using a pre - and post design with child psychiatric patients diagosed as having emotional and/or behavioural psychiatric problems. We hypothesize, first, that participation in Theraplay ${ }^{\circledR}$ will improve the quality of parent-child interaction. Second, we hypothesize that children's internalizing and externalizing symptoms will decrease as a consequence of participating in Theraplay®.

\section{Method}

\section{Participants}

The sample consisted of 18 children aged between 4 to $8(\mathrm{M}=4.42, \mathrm{SD}=1.54)$ who were patients at the Helsinki University Central Hospital's (HUCH) Child Psychiatric outpatient clinics in Espoo and Porvoo in 2007-2009. For 13 children, both parents participated and for 8 children, only the mother participated in the treatment together with the child (total 31 dyads, and 18 children, 11 boys 
and and 7 girls). Children met the following criteria: the outpatient child psychiatric team had examined them and behavioral and emotional problems were given as primary diagnosis according to ICD-diagnostic criteria. The outpatient team consist of child psychiatrist, psychologist, psychiatric nurse, social worker and speech and occupational therapists. The child psychiatric examinations consist of several meetings with the child and the parents and the use of structured assesments (e.g., structured psychiatric interviews, developmental psychological tests, structured parent-child videotaped assesments, parental anamnestic interviews, several standardized questionaires and observation in preschool or school settings, teacher evaluations etc.). Diagnoses are based on the whole examination process which typically lasts 2-3 months after which treatment (here: Theraplay® therapy) begins. Eight children had F93.9 (Childhood unspecified emotional disorder), eight children had F92.9 (Mixed disorder of conduct and emotion), 2 children had F94.1 (Selective mutism), and three children had also an additional diagnosis of R62.0 (Expressive Speech Delay / Mild cognitive Delay). The children showed no evidence of pervasive developmental disorder and were biological children of the parent(s). The children were not receiving medication or another form of psychotherapy during the study period. All parents gave their voluntary, informed consent for treatment and were informed of their rights to leave the treatment at any time. The study plan was approved by the ethical committee of HUCH.

\section{Measures}

Sociodemographic characteristics of the sample. The background information of the present study included child and parental age, marital status, parity and parental SES indexed by level of education. The education level ranged from the lowest category (compulsory 9 years of school) to highest (university or polytechnic degree) on a scale from one to three.

Children's internalizing and externalizing symptoms. The Child Behavior Checklist (CBCL; Achenbach, 1991) was used to assess internalizing and externalizing symptoms. The 113-item checklist is designed to quantify a broad range of clinically relevant behavioral and emotional problems, such as withdrawal, somatic complaints, anxiety and depression, thought, social and attention problems, and delinquent and aggressive behavior. Parents estimated the degree or frequency of each behavior in their child on a 3-point scale: 0 (not true), 1 (somewhat or sometimes true) or 2 (very true or often true). Scores are then summed and converted to T-scores (M 50, SD 10) on seven different syndrome scales (Emotionally Reactive, Anxious/Depressed, Somatic Complaints, Withdrawn, Sleep Problems, Attention Problems, and Aggressive Behavior), as well as five different 
DSM-oriented scales (Affective Problems, Anxiety Problems, Pervasive Developmental Problems, Attention Deficit/Hyperactivity Problems and Oppositional Defiant Problems). These scores combine to yield an Internalizing Problems, Externalizing Problems, and Total Problems composite score. Only Internalizing Problems and Externalizing Problems were examined in the present study (Tables 3 and 4). In two-parent families, mean of parental answers was used to describe the child's pre- and post intervention externalizing and internalizing symptoms. The manual for the CBCL reports adequate reliability and validity for scale scores (Achenbach, 1991), and it has also been validated and tested with Finnish child psychiatric samples (Sourander \& Piha, 1997).

Parent-child interaction. A semistructured videotaped protocol called the Marschak Interaction Method (MIM) (Marschak, 1960) was applied here. The MIM consists of nine playful tasks tapping various aspects of parenting, e.g., parental guiding capabilites ("Teach the child something the child doesn't know or can't do") emotional engagement and playfulness ("Put funny hats on each other") and nurturing and attuning qualities ("Put lotion on each other") (see Salo \& Booth, 2019). The parent and the child sit by a table, and the therapist asks the parent to read aloud each MIM task from a small card before doing the task. Parents are instructed to perform all the tasks with the child, and are reminded that there are no right or wrong ways of doing them. The therapist doesn't stay in the room, but monitors the family either via a one-way mirror or video. The MIM usually lasts about 30-45 minutes. In this study, to achieve rich qualitative information, the MIM observation was rated using two separate scoring scales and two scores: Dyadic Emotional Interaction Style and Emotional Availablity Scales.

Dyadic Emotional Interaction Style (D-EIS). D-EIS was developed specifically for scoring the MIM observation (Salo \& Mäkelä, 2006; Salo \& Booth, 2019). Each variable (except the parental representational quality) is scored both for parent's interaction as well as the child's interaction thus yielding altogether nine variables: Parental Guidance / Child Co-operation, Parental Engagement / Child Engagement, Parental Nurture / Child's acceptance of Nurture, Parental Playfullness / Child Playfullness, and Parental Representational Quality. The Parental Guidance/Child Co-operation scale assesses the parent's general ability to assist the child to orient to the overall situation and individual tasks so that they are meaningful and understandable and the child's attempts and willingness to take part in the mutual interaction. The Engagement scale evaluates the genuine reciprocal emotional contact from both parental and child sides. The Nurture scale evaluates the parent's skill in addressing the child's attachment needs. i.e., the need to stay close, to be regulated/comforted especially in times 
of stress, and the child's openness to seeking help and regulation when in need. Playfullness reflects an ability to engage in shared, relaxed, playful moments from both the parents and the child's sides. The Parents Representation scale assesses the quality and content of the narrative emerging from the parent's story to the child about about the time when he/she was a little baby. They were assessed on a 5-point Likert scale. A score of 5 or 4 indicates good or sufficient quality of interaction, and a score of 3 or lower indicates clinical concern. The validity and reliability of the scale has been evaluated to be good in a Finnish sample (Salo \& Mäkelä, 2006).

Two independent trained raters (Theraplay® Supervisors trained reliable for the D-EIS scoring) evaluated videotaped parent-child MIM tasks by the D-EIS scales blind to the intervention phase (pre- or post). The interrater reliabilities ranged between .87-91 on different scales.

For the D-EIS, separate summary scores were built: Maternal and paternal pre- and postintervention parental scores (consisting of averaged parental guidance, engagement, nurture, playfulness and representation of the child) and child pre- and post-intervention scores towards the mother and towards the father (consisting of child co-operativeness, engagement, response to nurturing and playfulness).

Emotional Availability Scales (EAS 4th ed; Biringen, 2008) is a widely used scale for assessing the emotional availability (EA) within a parent-child dyad. This perspective suggests that at the core of a healthy mother-child relationship is the maternal capacity to read and respond to the infant's emotional cues, and the child's reciprocity of emotional responding (Biringen \& Easterbrooks, 2012; Biringen, Derscheid, Vliegen, Closson, \& Easterbrooks, 2014). The EA includes sensitivity, structuring, nonhostility and nonintrusiveness from the maternal side and responsiveness and involvement from the child's side. Sensitivity and nonhostility refer to capacity for expressing positive emotions towards the child while controlling negative emotions. In turn, structuring and nonintrusiveness refer to the ability to guide the child in everyday interactions while taking into account the child's initiatives and developmental level. The child's side of the EA involves responding with positive emotions and initiatives towards the adult. The highest score (7) refers to the optimal presence of these qualities and the lowest (1) to their complete absence.

A trained rater (first author) rated all the tapes, and $20 \%$ were coded by another coder reliable in the EAS 4th edition and trained by Z. Biringen (second author), with five tapes checked together with the method developer (Z.B). All raters were blind to the intervention ohase (pre or post). Interrater reliabilities ranged between .79 and.92. For final analyses, summary scores were built: 
Maternal and paternal pre- and post-intervention EA (consisting of averaged sensitivity, structuring, nonintrusiveness and nonhostility) and child pre- and post-intervention EA towards the mother and towards the father (consisting of averaged child responsiveness and child involvement).

\section{Procedure}

Theraplay ${ }^{\circledR}$ therapy model. Theraplay® therapy was conducted at the outpatient clinics once a week. Two therapists were assigned to each family, one working with the parents and the other with the child. Pre-intervention measurements comprising videotaped observation of the parent-child relationship and study questionnaires were conducted by both therapists. The assessment and preparation portion of the Theraplay® process began with parent interviews using a semi-structured MIM-interview related to their own attachment histories, and relational history with the child (Salo \& Booth, 2019). Prior to the child therapy sessions, parents first participated in a Parent Theraplay® session where the therapists introduced the treatment room, and demonstrated all Theraplay® activities to the parent(s). The goal was to familiarize the parent(s) with the setting, to further establish treatment goals, and to help them mentalize how the situation might feel from the child's perspective.

The weekly Theraplay® sessions were made up of adult-led interactive, non-symbolic playful activities suited to the child's developmental level. The five main goals are to provide: 1) guidance, comprising structure and challenge (e.g., adult being in charge of the planned activities and partnering with the child to achieve slightly more difficult tasks over time so that child experienced a feeling of mastery), 2) engagement (e.g., making positive interaction possible, facilitating joint attention and focusing on interpersonal relations rather than object focused play), and 3) nurture (e.g., calming and caretaking). The overall goal throughout the sessions was playfullness, i.e., making sure that the main aim was to have fun together rather than to perform. The interactive activities included for example blowing soap bubbles, making a stack of hands, and jumping over pillows. In the beginning of Theraplay ${ }^{\circledR}$, the parents and their therapist observed a 30-minute play session between the child and child's therapist from behind a one-way mirror or via video transmission. Typically in session 3 or 4 the parents joined the session play with the child and therapist to participate in the play and care, to assist/support their child and to take turns leading the interaction with the help of the therapist. The intention of the process was that the combination of observation, reflection and direct participation would give the parent a new understanding and motivation of how to attune to the child's 
needs of structure, engagement etc., as well as the child a new experience of their parent. Towards the end of treatment, parents took increasing responsibility for leading the session and the activities.

All the sessions were videotaped, and the parents (or one parent) met with both therapists in separate reflective videofeedback sessions after every third Theraplay® play session. In the reflective videofeedback, the aim was to enhance parental perceptions of the child, focusing especially on attachment needs and acknowledging the child's increasing initiatives for positive interaction. These observations were discussed in order to increase parental understanding of the child's feelings and thoughts, e.g., how the child's avoidant behaviors in a Theraplay® ${ }^{\circledR}$ session might be related to internal feelings of fear of being rejected. Parents were also directly taught Theraplay® skills through instruction, modelling and role-playing with them. As treatment proceeded, reflective video feedback discussions also focused on how parent(s) understood themselves and how their own attachment history may have affected the way they were able to read and interpret the child's attachment-related signals. Additionally, in order to re-inforce parental guidance skills, discussions emphasized how to avoid negative feedback and commanding language, when facing child resistance or avoidance but instead to give clear and safe adult guidance. Finally, with new understanding about attachment relationship and what constitutes good guidance, reflective discussions focused on generalizing the Theraplay ${ }^{\circledR}$ skills into the every-day experience, i.e., what was going on at home and how Theraplay ${ }^{\circledR}$ skills could help parents apply a new way of thinking and behaving with the child in these situations. Parents were also given homework between the weekly sessions to adapt the new skills learned in Theraplay® into everyday life, e.g., adding a relaxing back massage into evening routines.

The mean length of Theraplay was 20.35 sessions ( $\mathrm{SD}=3.2$, range: $13-24$ sessions). Posttest measurements comprising videotaped parent-child interaction measurement and study questionnaires were conducted 2-3 months post-intervention (for practical reasons the schedule for the post-test measurement varied). The families did not receive any other treatment before the post-testing. Theraplay® sessions were held weekly. For practical reasons (holidays, sickness of the child etc.) there were sometimes longer pauses, lasting at the maximum 2-3 weeks. Therapists were all experienced clinicians (three psychologists, one occupational therapist) working at the child psychiatric hospital outpatient units. They were all certified Theraplay ${ }^{\circledR}$-therapists trained by The Theraplay ${ }^{\circledR}$ Institute's accredited Finnish Theraplay Association's Trainers. This training lasted 2-3 years and consisted of over 200 hours of Theraplay® and over 30 supervisory sessions with Theraplay® Trainer-Supervisor. All therapists in this study participated in monthly group supervision held by an experienced child 
psychiatrist and Theraplay® Supervisor-Trainer. The supervision made it possible to ensure Theraplay ${ }^{\circledR}$ treatment integrity across therapists. In the supervisions, the progress of the treatment was followed by supervision discussion of video recordings of treatment sessions, including both Theraplay® and reflective video-feedback work with the parents.

Please insert Table 1 around here

\section{Analysis strategy}

The associations between background and study variables (internalizing and externalizing symptoms and parental and child ratings on D-EIS and EA) were examined with Pearson's correlations. To assess whether background variables were associated with change in study variables, difference scores (pre - postnatal score) were constructed representing change in pre- to postnatal internalizing and externalizing symptoms, maternal and paternal D-EIS/MIM and EA and child DEIS/MIM and child EA towards the mother and the father. We then examined whether the difference scores (i.e., change in study variables) associated with any of the background variables: mother's, father's and child's age, number of therapy sessions, maternal and paternal education level (lower, consisting of high school or vocational training, vs. higher, consisting of bachelor or master degree), marital status (married or cohabiting vs. single) parity (primi- vs. multiparous) and child sex. Continuous variables were examined with Pearson's correlations and categorical variables with Student's t-tests. Due to non-significant findings on background variables, and small sample size, covariates were not used in the main analyses, as the appropriate statistical methods did not allow adding of covariates.

Paired-sample t-tests were used to answer all three research questions: 1) Change in child internalizing and externalizing symptoms from pre- to post-intervention, 2) Change in maternal and paternal D-EIS/MIM and child D-EIS/MIM towards the mother and the father from pre- to postintervention, and 3) Change in maternal and paternal EA and child EA towards the mother and the father from pre- to post-intervention.

\section{Results}

\section{Descriptive statistics}

Sociodemographic background characteristics are shown in Table 2. The sample is representative of Finnish parents (Vuorenmaa, 2019). The parents were all Finnish speaking and they were 
mostly married or co-habiting (91\%), and with higher than mere compulsory level of eduation (85\%). Most participating children had siblings. Correlations between study variables are presented in Table 3. The results showed, for example, that higher child's pre-intervention internalizing symptoms were associated with lower child's pre-intervention interaction quality as measured with MIM, whereas preintervention externalizing symptoms correlated positively with higher child interaction qualities post-test. The MIM interaction variables correlated significantly between maternal and child scores across pre- and post-tests, while EA variables only between maternal scores.

None of the background variables (number of therapy sessions, child's, mother's or father's age, parity, mother's and father's educational level and child sex) were associated with change in child mental health symptoms or change in parent-child interactions.

\section{Please insert Tables 2 and 3 around here}

\section{Change in child's parent-child interaction quality and internalizing and externalizing symptoms}

Table 4 shows the means and standard deviations for study variables pre- and postpartum and the significance of pre- to post-intervention change. Our hypothesis was supported related to change in mother-child interaction quality, as the results showed a significant increase from pre- to post-intervention in maternal and child interaction variables, indicated by changes measured both with D-EIS and EA. Concerning father-child interaction quality, our hypothesis received partial support in that there was a significant pre- to post-intervention increase in paternal interaction quality (indicated by both D-EIS and EA) and in child interation quality as indicated by D-EIS. Change in child EA was not significant, but was in the expected direction. Furthermore, in accordance with our second hypothesis, paired samples t-tests showed a significant decrease in child externalizing, and internalizing symptoms from pre- to post-intervention. Thus, results showed that the mean levels for CBCL total scores changed from being in the clinical range (over 60) to normal range (hovering around 50) in mothers or near normal in the fathers. The mean levels for the parent-child interaction scores showed similarly a change from the clinically worrysome level (below 5 in the EA and below 3,5 in the MIM) to normative or nearly normative especially in terms of the parent side of interaction.

\section{Please insert Table 4 around here}




\section{Discussion}

The results of this pilot study in a child psychiatric outpatient setting showed that Theraplay® was able to increase the quality of parent-child interaction and to reduce both child internalizing and externalizing symptoms from pre- to post-treatment. These results suggest that working at the parent-child interactional level might be helpful in terms of both symptom reduction as well as generally improving the developmental context with children suffering from clinical levels of emotional and behavioral problems. The preliminary findings are important as there is an increase of early childhood emotional and behavioral diagnoses (e.g., Atladottir et al., 2014; Schwarz \& Cohen, 2013), and children's psychiatric problems create a heavy burden to parents. The parent-child relationship is agreed to be the most crucial factor for healthy development, and thus improving parenting skills and reciprocal joy and emotional engagement in the psychiatric treatment setting is vital.

The need for parental educational and psychotherapeutic interventions has been acknowledged, and many models have shown promising results in addressing either the parental guiding skills (Gardner et al.., 2015; Yap et al., 2016) or enhancing sensitivity and emotional attachment (Bakermans-Kranenburg et al., 2003). However, previous studies have often focused on separate dimensions of the parent-child relationship, such as the limit-setting practices, or are mainly designed for younger age groups. Few studies have also examined high-risk children with clinically diagnosed levels of emotional and behavioral problems. Parents of children who have clinical level of emotional and/or behavioral problems are, however, likely to have many problems in different areas of parenting as their children are often both uncooperative, easily dysregulated as well as emotionally less engaged. Thus, more integrative treatment models that comprehensively tackle multi-level dyadic and psychiatric problems and are applicable also to older children are very needed. Theraplay® represents such an integrative model combining elements from both social learning and attachment traditions: focusing on both helping the parents to structure and guide their child in developmentally appropriate ways, including limit-setting skills, as well as creating emotional engagements, and offering nurture on the basis of the child's attachment cues. Also, the special goal in Therapay is increasing joyfulness - a quality likely to be missing in families where children have serious emotional and/or behavioral problems. Thus, the results from the present pilot study may be seen as promising, as parents and their 
children with clinical levels of emotional and behavioral problems often exhibit problems in many areas of parent-child interaction.

Furthermore, Theraplay® also utilizes intensive intervention methods by including children and parents both in the play sessions as well as working with parents-only in separate videofeedback sessions. This can be considered an advance in clinical setting, as compared to only parentwork or child-centered therapies. Children with psychiatric disorders/ problems generally exhibit severe emotion regulation problems, needing parental assistance and ability to read their signs of attachment needs (Zeanah et al., 2011). Theraplay® acknowledges the difficulties parents have in guiding their children and creating emotionally attuned and synchronized responses, e.g., by systematically and experientially enhancing parenting skills and confidence. The therapist's role is very active especially in the beginning, as the therapist takes charge in trying to find new and positively attuned ways of relating with the child. Having the parents observer with their own interpreting therapist at their disposal keeps them participating, but also gives them space to reflect and develop deeper understanding of their own struggles, e.g., how difficult it is to interact with the child, as the therapist often faces the same forms of avoidance or resistance in the sessions. Importantly, the guidance of the professional makes it easier for the parent/s to stay open-minded, and curiously explore new ways of guiding, engaging and regulating the child. When parents have gained new insights, the therapist will directly help them in these new ways to interact with their child. In the middle sessions of Theraplay®, the therapist still provides the parents support and encouragement in their efforts to respond to and reflect on their mutual interaction with the child. Finally, towards the end, parents feel more confident in relating with their child and they can start generalizing the new skills into their everyday life. Having these direct, hands-on experiences with the child especially in the beginning of Theraplay®, will nevertheless give valuable insight to therapist also in trying to learn what works best with this particular child throughout the Theraplay® process. Adding the separate video-reflective discussions, where the previous sessions are viewed together with the parent/s, serves further to strenghten the parental understanding of their relationship with the child. Having video-reflection work as part of the treatment model has also previously been found to add to the efficacy of the intervention (Bakermans-Kranenburg et al., 2003).

Finally, the unique characteristic of Theraplay® is the goal of creating fun moments-ofmeeting by using play activities as an avenue for a more general change in the parent-child relationship. Some previous parent-child interaction interventions, such as the PCIT, have also utilized 
play with promising results (Pearl et al., 2012). However, the special use of attachment-based play and the focus on positive affects, synchrony and mutual regulation in flexible and attuned ways is what sets Theraplay® apart from many other parenting- and attachment-based intervention models. The special protective importance of play and positive affects may be especially relevant when children have clinical levels of emotional and behavioral symptoms, as previous research had indicated longitudinal reductions in symptoms when parents show positive affects (e.g., Lunkenheimer et al., 2011). In general, the preventive and healing significance of positive emotions and mutually felt joy as essential mental health promoters has become an important topic in health psychology (Fosha, Siegel, \& Solomon, 2009). Theraplay® was originally based on the very idea that the use of attachment-based play activities, which parents naturally use when bonding with their young children, would help bringing parents and their children closer (Booth \& Jernberg, 2009). As such, Theraplay® may serve as an intervention model where not only the symptom reduction but also the increase of preventive and positive mechanisms (here: the quality of parent-child interaction) is possible.

The results also showed a decrease in both internalizing as well as externalizing symptoms. Children in this sample were already diagnosed with emotional and behavioral psychiatric diagnoses. As the goal of any child psychiatric intervention is to reduce the symptoms, the present results seem to indicate that Theraplay® served as a focused intervention in terms of the presenting problems also. It is likely that in the individually tailored Theraplay® therapies, the therapist were able to specifically address the main difficulties of each individual child, be it more emotionally expressed symptomology such as anxiety or depressive symptoms or behavioral problems. This tailoring and individualized goal setting using the Theraplay® model may be important, given that different symptom profiles may require different strategies from the parental side, for example using more engaging and nurturing activities with a withdrawn child and more challenging and structuring activities with more behaviorally resisting child. Thus, the benefit of using Theraplay® as opposed to more strictly manualized forms of parenting or attachment-based interventions may be the flexibility in terms of adjusting the core model to address each child's symptom profile as well as the difficulties present in that particular parent-child relationship. Also, as highlighted by both parenting and attachment theorists, it is likely that with improving parent-child interaction quality, the child's symptoms would decrease. Thus, having these separate, yet related treatment goals seems clinically reasonable. Finally, as the present sample comprised children of varying ages (4-8 years), the results suggest that Theraplay ${ }^{\circledR}$ could be used effectively with symptomatic preschoolers as well as school- 
aged children which is also consistent with other studies exploring Theraplay® among preschoolers (Wettig et al., 2011), and with older children (Siu, 2009, 2014).

The major limitation of the present pilot study is that there was lack of control group and a RCT design. At the time of the study, it was not possible to organize a control group even through a waiting-list procedure for both practical and ethical reasons, as some children would have had to wait for many months for the start of the treatment, and there was no equivalent short-term treatment available in the child psychiatric units. Although promising, the present results need to be confirmed in a randomized trial in the future and also using a longer post-measurement period, for example comparing Theraplay® to other existing and used treatment models in Finland or treatment as usual and following the results with several post-treatment measurements. Furthermore, although we obtained qualitatively rich information about the quality of parent-child interaction through the use of videos and two different scoring methods, having a measure assessing the parental reflectiveness would have given a more complete picture of the impact of Theraplay®. Although parents were interviewed qualitatively as part of the Theraplay® treatment process, and the therapist had information about the level of parental reflectiveness which they used when planning and executing the Theraplay®, no systematized assessment was implemented. In future studies, using a parental reflective interview such as PDI (Slade et al., 2007) would give more precise information on the role it has on the parent-child interactions on a behavioral level, and whether changes in parental mentalizing facilitate changes in parent-child behavioral interactions. In this line, using a larger sample size and controlling for various potentially confounding factors (such as parental trauma history, mental illnesses etc.) is also important. With a small sample size the use of statistical methods is also limited, and it was not possible to e.g. use covariates or look whether improvements in parent-child interactions mediated improvements in psychiatric symptoms.

Despite these limitations, this study represents a first effort in studying Theraplay® therapy among children in a child psychiatric outpatient setting. The results suggest that a randomized study in clinical settings is clearly warranted. Given the integrative, multi-focus framework and special emphasis on resiliency and health promoting factors, the results underline the clinical potential of Theraplay®. 
Table 1. Structure and treatment elements of Theraplay®

\begin{tabular}{|c|c|c|c|c|}
\hline \multicolumn{5}{|l|}{ Theraplay ${ }^{\circledR}$} \\
\hline \multicolumn{5}{|l|}{ Pre-therapy } \\
\hline & \multirow{2}{*}{\multicolumn{4}{|c|}{ Parental attachment history, relational history with the child }} \\
\hline Parent(s) & & & & \\
\hline Parent-Child & \multirow{2}{*}{\multicolumn{4}{|c|}{ Marschak Interaction Method ${ }^{1}$}} \\
\hline Interaction Video & & & & \\
\hline Study & & & & \\
\hline questionnaires & \multicolumn{4}{|l|}{$\mathrm{CBCL}^{2}$} \\
\hline Parent(s) & \multirow{3}{*}{\multicolumn{4}{|c|}{$\begin{array}{l}\text { Practice the Theraplay® activities, mentalizing the child's } \\
\text { perspective, information about the goals of treatment tailored } \\
\text { to each parent-child dyad }\end{array}$}} \\
\hline Theraplay® & & & & \\
\hline Session & & & & \\
\hline & $\begin{array}{l}\text { Guidance (Structure } \\
\text { and Challenge) }\end{array}$ & Engagement & Nurture & $\begin{array}{l}\text { Parental } \\
\text { Reflectivess }\end{array}$ \\
\hline \multicolumn{5}{|l|}{ Sessions 1-3. } \\
\hline Engaging the child & $\begin{array}{l}\text { Therapist leading the } \\
\text { play activities using } \\
\text { Encouragement and } \\
\text { positive challenging, } \\
\text { e.g., popping soap } \\
\text { bubbles with } \\
\text { different body parts }\end{array}$ & $\begin{array}{l}\text { Getting to know } \\
\text { the child using } \\
\text { suprising, fun } \\
\text { ways of } \\
\text { approaching, e.g., } \\
\text { measuring the } \\
\text { child's smile }\end{array}$ & $\begin{array}{l}\text { Checking for } \\
\text { hurts, lotioning } \\
\text { the child's hands, } \\
\text { making hand } \\
\text { prints etc. }\end{array}$ & $\begin{array}{l}\text { Noticing and } \\
\text { naming unique, } \\
\text { positive ways } \\
\text { of the child's } \\
\text { attachment- } \\
\text { based } \\
\text { responses and } \\
\text { intitiatives in } \\
\text { social } \\
\text { interaction } \\
\text { using } \\
\text { attachment- }\end{array}$ \\
\hline
\end{tabular}


framework, e.g., exploring

hidden needs

of caretaking

under

avoidance

rather than

overt

behavior.

Session 4-10.

Guiding the

Dealing with

Helping parent(s)

Helping parent(s)

Noticing and

Parent(s) to use the

resistance to change

to enage with

use gentle touch to

naming

Dimensions in the

e.g., turning the

their child, e.g.

give nurture

parent's

Session

child's resistance to checking both of

attachment-

adult structure into an their eye colours

based

activity

responses to

Helping the parents

their children

to give proactive in the sessions,

guidance in each

e.g., exploring

activity

why the child's

resistance

might be

experienced as

rejection

Sessions 10-20

1) Transferring

Helping the parents

Supporting the

Supporting the

Noticing and

Leadership of the

to find flexible,

parents to findi

natural use of

naming how

Session to the

positive ways of

and use all

physical closeness

parent's and

Parents

being charge and

opportunitues in

throughout the

the child's

the session to

sessions

reactions are 


\begin{tabular}{|c|c|c|c|c|}
\hline & keeping firm with & engage with the & & related to each \\
\hline & limits & child & & other, noticing \\
\hline \multirow{6}{*}{$\begin{array}{l}\text { 2) Generalizing } \\
\text { into everyday life } \\
\text { using homework }\end{array}$} & & E.g., finding a & E.g., making & the positive \\
\hline & E.g., how to structure & joint hobby for & back-massage a & cycles of \\
\hline & evening routines & the parent and the & regular evening & interaction and \\
\hline & using proactive, fun & child & routine & intentitional \\
\hline & and surpising adult- & & & states of mind \\
\hline & leadership skills & & & underneath \\
\hline
\end{tabular}

\begin{tabular}{ll}
\hline $\begin{array}{l}\text { Post-therapy } \\
\text { Interviewing the }\end{array}$ & $\begin{array}{l}\text { Parent's experience of Theraplay®, making a plan for check-ups and following } \\
\text { Parent(s) }\end{array}$ \\
$\begin{array}{l}\text { treatment } \\
\text { Interaction Video }\end{array}$ & Marschak Interaction Method $^{1}$ \\
Study & \\
questionnaires & CBCL $^{2}$
\end{tabular}

${ }^{1}$ The Marcshak Interaction Method (MIM) is a videotaped, semi-structured parent-child observation.

2 The Child Behavior Checklist (CBCL; Achenbach, 1991) 
Table 2. Distributions and Means of the Parental Education Level, Marital Status, Parity and Age

\begin{tabular}{|c|c|c|c|c|c|c|}
\hline \multirow{3}{*}{ Educational level } & \multirow[b]{2}{*}{$n$} & \multirow[b]{2}{*}{$\%$} & \multicolumn{2}{|c|}{ Mothers $(n=18)$} & \multicolumn{2}{|c|}{ Fathers $(n=13)$} \\
\hline & & & & $\%$ & $\mathrm{n}$ & $\%$ \\
\hline & & & & & & \\
\hline \multicolumn{7}{|l|}{ Low (compulsory 9} \\
\hline \multicolumn{7}{|l|}{ years of school) } \\
\hline & 5 & $15 \%$ & 3 & $17 \%$ & 21 & $16 \%$ \\
\hline Medium (high-school & & & & & & \\
\hline or vocational school) & 16 & $49 \%$ & 9 & $50 \%$ & 53 & $38 \%$ \\
\hline $\begin{array}{l}\text { High (university or } \\
\text { polytechnic degree) }\end{array}$ & 12 & $36 \%$ & 6 & $33 \%$ & 62 & $46 \%$ \\
\hline \multicolumn{7}{|l|}{ Marital status } \\
\hline Married & 20 & $61 \%$ & & & & \\
\hline Cohabiting & 10 & $30 \%$ & & & & \\
\hline Single & 3 & $9 \%$ & & & & \\
\hline \multicolumn{7}{|l|}{ Parity } \\
\hline 1 or more siblings & 14 & $78 \%$ & & & & \\
\hline Only child & 4 & $22 \%$ & & & & \\
\hline \multirow[t]{2}{*}{ Parental Age } & $\mathrm{M}$ & SD & $\mathrm{M}$ & SD & $\mathrm{M}$ & SD \\
\hline & 34,90 & 6,32 & 33,6 & 5,9 & 36,8 & 6,8 \\
\hline
\end{tabular}


Table 3. Correlations between study variables

\begin{tabular}{|c|c|c|c|c|c|c|c|c|c|c|c|c|c|c|c|c|c|c|c|c|}
\hline & 1 & 2 & 3 & 4 & 5 & 6 & 7 & 8 & 9 & 10 & 11 & 12 & 13 & 14 & 15 & 16 & 17 & 18 & 19 & 20 \\
\hline \multicolumn{21}{|c|}{ Child mental health symptoms } \\
\hline 1. Pre ext & - & & & & & & & & & & & & & & & & & & & \\
\hline 2. Pre int & -.22 & - & & & & & & & & & & & & & & & & & & \\
\hline 3. Post ext & $.98 * * *$ & -.23 & - & & & & & & & & & & & & & & & & & \\
\hline 4. Post int & -.06 & $.93 * * *$ & -.07 & - & & & & & & & & & & & & & & & & \\
\hline \multicolumn{21}{|c|}{ Mother-child interaction } \\
\hline 5. Pre EA mother & .30 & -.31 & .24 & -.31 & - & & & & & & & & & & & & & & & \\
\hline 6. Pre EA child & -.03 & -.44 & -.12 & $-.50 *$ & $.56^{*}$ & - & & & & & & & & & & & & & & \\
\hline 7. Post EA mother & .43 & -.09 & .42 & -.02 & $.69 * *$ & -.01 & - & & & & & & & & & & & & & \\
\hline 8. Post EA child & .39 & -.34 & .36 & -.28 & .27 & .23 & .29 & - & & & & & & & & & & & & \\
\hline $\begin{array}{l}\text { 9. Pre MIM } \\
\text { mother }\end{array}$ & .31 & -.23 & .28 & -.23 & $.83 * * *$ & .45 & $.61 *$ & .23 & - & & & & & & & & & & & \\
\hline 10. Pre MIM child & .18 & $-.54 *$ & .15 & $-.55^{*}$ & $.71 * *$ & $.79 * * *$ & .22 & .31 & $.75^{* *}$ & - & & & & & & & & & & \\
\hline $\begin{array}{l}\text { 11. Post MIM } \\
\text { mother }\end{array}$ & .32 & -.17 & .27 & -.18 & $.72 * *$ & .43 & $.71 * *$ & .06 & $.84 * * *$ & $.64 *$ & - & & & & & & & & & \\
\hline $\begin{array}{l}\text { 12. Post MIM } \\
\text { child }\end{array}$ & $.67 * *$ & -.32 & $.65^{* *}$ & -.27 & $.64 *$ & .31 & $.74 * *$ & .48 & $.60 *$ & $.52 *$ & $.69 * *$ & - & & & & & & & & \\
\hline \multicolumn{21}{|c|}{ Father-child interaction } \\
\hline 13. Pre EA father & -.28 & .26 & -.22 & .29 & -.47 & .40 & $-.77 *$ & -.08 & -.04 & .62 & -.48 & -.51 & - & & & & & & & \\
\hline 14. Pre EA child & -.11 & -.25 & -.08 & -.02 & .39 & .21 & .02 & .18 & .61 & .64 & .21 & -.21 & .44 & - & & & & & & \\
\hline 15. Post EA father & -.17 & .36 & -.12 & .32 & .11 & .43 & -.39 & .49 & .31 & .65 & -.06 & -.06 & $.87^{* *}$ & .28 & - & & & & & \\
\hline
\end{tabular}




\begin{tabular}{|c|c|c|c|c|c|c|c|c|c|c|c|c|c|c|c|c|c|c|c|c|}
\hline 16. Post EA child & .13 & .26 & -.18 & .39 & .18 & .18 & -.21 & .56 & .24 & .50 & -.16 & -.00 & $.75^{*}$ & .44 & $.91 * * *$ & - & & & & \\
\hline $\begin{array}{l}\text { 17. Pre MIM } \\
\text { father }\end{array}$ & -.25 & .10 & -.18 & .11 & -.09 & .59 & -.46 & .27 & .14 & $.77^{*}$ & .05 & -.30 & $.86^{* *}$ & .55 & .61 & .53 & - & & & \\
\hline 18. Pre MIM child & -.26 & -.20 & -.23 & -.10 & .09 & .45 & -.31 & .20 & .44 & $.82 * *$ & .11 & .30 & .55 & $.79 * *$ & .22 & .17 & $.70^{*}$ & - & & \\
\hline $\begin{array}{l}\text { 19. Post MIM } \\
\text { father }\end{array}$ & .15 & .31 & .15 & .27 & .35 & .36 & -.09 & .24 & $.72 *$ & $.70^{*}$ & .37 & .00 & $.94 * * *$ & .52 & $.77 * *$ & $.71 *$ & $.84 * *$ & .51 & - & \\
\hline $\begin{array}{l}\text { 20. Post MIM } \\
\text { child }\end{array}$ & .14 & .33 & .11 & .38 & .46 & .34 & -.02 & .41 & .54 & $.68^{*}$ & .20 & .23 & .60 & .57 & $.73 *$ & $.73 *$ & .42 & .52 & $.68^{*}$ & - \\
\hline
\end{tabular}


Table 4. Change in pre-to post-intervention study variables

\begin{tabular}{lcccccc}
\hline & \multicolumn{2}{c}{ Pre-intervention } & \multicolumn{2}{c}{ Post-intervention } & \multicolumn{2}{c}{ Significance of change } \\
\hline & $\mathrm{M}$ & $\mathrm{Sd}$ & $\mathrm{M}$ & $\mathrm{Sd}$ & $t(d f)$ & $p$ \\
Mother's EA & 4.70 & 0.64 & 5.43 & 0.57 & $t(14)=-6.00$ & $<.001$ \\
Father's EA & 4.69 & 0.71 & 5.74 & 0.70 & $t(7)=-5.66$ & $\mathbf{. 0 0 1}$ \\
Child's EA to mother & 3.94 & 0.61 & 4.77 & 0.50 & $t(16)=-4.66$ & $<.001$ \\
Child's EA to father & 4.05 & 0.81 & 4.70 & 0.91 & $t(7)=-2.23$ & .061. \\
Mother's MIM & 2.80 & 0.57 & 3.41 & 0.41 & $t(14)=-7.34$ & $<.001$ \\
Father's MIM & 2.80 & 0.54 & 3.61 & 0.52 & $t(7)=-5.79$ & $\mathbf{. 0 0 1}$ \\
Child's MIM to mother & 2.46 & 0.41 & 3.21 & 0.37 & $t(14)=-8.00$ & $<.001$ \\
Child's MIM to father & 2.59 & 0.46 & 3.53 & 0.42 & $t(7)=-5.66$ & $\mathbf{. 0 0 1}$ \\
Internalizing symptoms & 62.71 & 13.48 & 56.21 & 10.76 & $t(16)=5.08$ & $<.001$ \\
Externalizing symptoms & 64.09 & 12.33 & 61.29 & 10.88 & $t(16)=4.06$ & .001 \\
\hline
\end{tabular}




\section{References}

Achenbach, T. M. (1991). Manual for the Child Behavior Checklist/4-18 and 1991 profile. University of Vermont, Department of Psychiatry.

Atladottir, H. O., Gyllenberg, D., Langridge, A., Sandin, S., Hansen, S. N., Leonard, H., ... \& Hultman, C. M. (2015). The increasing prevalence of reported diagnoses of childhood psychiatric disorders: a descriptive multinational comparison. European Child \& Adolescent psychiatry, 24(2), 173-183.

Bakermans-Kranenburg, M. J., Van Ijzendoorn, M. H., \& Juffer, F. (2003). Less is more: metaanalyses of sensitivity and attachment interventions in early childhood. Psychological Bulletin, 129(2), 195.

Belsky, J. (1997a). Theory testing, effect-size evaluation, and differential susceptibility to rearing influence: The case of mothering and attachment. Child Development, 68(4), 598-600.

Belsky, J. (1997b). Variation in susceptibility to environmental influence: An evolutionary argument. Psychological Inquiry, 8(3), 182-186.

Belsky, J. (2005). Differential susceptibility to rearing influence. Origins of the social mind: Evolutionary psychology and child development, 139-163.

Biringen, Z. (2008). Emotional Availability (EA) Scales Manual, 4th edtion. Part 1: Infancy/Early Childhood version (child aged 0-5 years). Unpublished manuscript. Boulder.

Biringen, Z., \& Easterbrooks, M. A. (2012). Emotional availability: concept, research, and window on developmental psychopathology. Development and Psychopathology, 24, 1-8.

Biringen, Z., Derscheid, D., Vliegen, N., Closson, L., \& Easterbrooks, M. A. (2014). Emotional availability (EA): Theoretical background, empirical research using the EA Scales, and clinical applications. Developmental Review, 34, 114-167.

Booth, P. B., \& Jernberg, A. M. (2009). Theraplay®: Helping parents and children build better relationships through attachment-based play. John Wiley \& Sons.

Camoirano, A. (2017). Mentalizing makes parenting work: a review about parental reflective functioning and clinical interventions to improve it. Frontiers in Psychology, 8. 
Carlson, E. A., Sampson, M. C., \& Sroufe, L. A. (2003). Implications of attachment theory and research for developmental-behavioral pediatrics. Journal of Developmental \& Behavioral Pediatrics, 24(5), 364-379.

Cole, P. M., Teti, L. O., \& Zahn-Waxler, C. (2003). Mutual emotion regulation and the stability of conduct problems between preschool and early school age. Development and Psychopathology, 15(1), 1-18.

Deater-Deckard, K., Atzaba-Poria, N., \& Pike, A. (2004). Mother-and father-child mutuality in Anglo and Indian British families: A link with lower externalizing problems. Journal of Abnormal Child Psychology, 32(6), 609-620.

Dubois-Comtois, K., Moss, E., Cyr, C., \& Pascuzzo, K. (2013). Behavior problems in middle childhood: The predictive role of maternal distress, child attachment, and mother-child interactions. Journal of Abnormal Child Psychology, 41(8), 1311-1324.

Eyberg, S. M., Nelson, M. M., \& Boggs, S. R. (2008). Evidence-based psychosocial treatments for children and adolescents with disruptive behavior. Journal of Clinical Child \& Adolescent Psychology, 37(1), 215-237.

Feldman, R. (2003). Infant-mother and infant-father synchrony: The coregulation of positive arousal. Infant Mental Health Journal: Official Publication of The World Association for Infant Mental Health, 24(1), 1-23.

Feldman, R. (2012). Oxytocin and social affiliation in humans. Hormones and Behavior, 61(3), 380391.

Field, T. (2014). Massage therapy research review. Complementary Therapies in Clinical Practice, 20(4), 224-229. 
Fogel, A. (1993). Developing through relationships: Origins of communication, self, and culture. London: Harvester-Wheatsheaf, and Chicago: University of Chicago Press.

Fonagy, P., Steele, M., Steele, H., Moran, G. S., \& Higgitt, A. C. (1991). The capacity for understanding mental states: The reflective self in parent and child and its significance for security of attachment. Infant Mental Health Journal, 12(3), 201-218.

Fosha, D., Siegel, D. J., \& Solomon, M. (Eds.). (2009). The healing power of emotion: Affective neuroscience, development \& clinical practice. WW Norton \& Company

Francis, Y. J., Bennion, K., \& Humrich, S. (2017). Evaluating the outcomes of a school based Theraplay® project for looked after children. Educational Psychology in Practice, 33(3), 308-322.

Gardner, F., Montgomery, P., \& Knerr, W. (2015). Transporting evidence-based parenting programs for child problem behavior (age 3-10) between countries: Systematic review and metaanalysis. Journal of Clinical Child \& Adolescent Psychology, 45(6), 749-762.

Ginsburg, K. R. (2007). The importance of play in promoting healthy child development and maintaining strong parent-child bonds. Pediatrics, 119(1), 182-191.

Juffer, F., Bakermans-Kranenburg, M. J., \& van IJzendoorn, M. H. (2017). Pairing attachment theory and social learning theory in video-feedback intervention to promote positive parenting. Current Opinion in Psychology, 15, 189-194.

Harrist, A. W., Pettit, G. S., Dodge, K. A., \& Bates, J. E. (1994). Dyadic synchrony in mother-child interaction: Relation with children's subsequent kindergarten adjustment. Family Relations, 417-424.

Huber, A., McMahon, C., \& Sweller, N. (2015). Improved child behavioural and emotional functioning after Circle of Security 20-week intervention. Attachment \& Human Development, 17(6), 547-569.

Keenan, K., \& Shaw, D. S. (1995). The development of coercive family processes: The interaction between aversive toddler behavior and parenting factors. Coercion and punishment in long-term perspectives, 165-180. 
Kok, R., Linting, M., Bakermans-Kranenburg, M. J., van IJzendoorn, M. H., Jaddoe, V. W., Hofman, A., .. \& T Tiemeier, H. (2013). Maternal sensitivity and internalizing problems: Evidence from two longitudinal studies in early childhood. Child Psychiatry \& Human Development, 44(6), 751-765.

Lunkenheimer, E. S., Olson, S. L., Hollenstein, T., Sameroff, A. J., \& Winter, C. (2011). Dyadic flexibility and positive affect in parent-child coregulation and the development of child behavior problems. Development and Psychopathology, 23(2), 577-591.

Maccoby, E. E. (2015). Historical overview of socialization research and theory. In J. E. Grusec \& P. D. Hastings (Eds.), Handbook of socialization theory and research, pp. 3-32. New York, NY: Guilford.

Madigan, S., Moran, G., Schuengel, C., Pederson, D. R., \& Otten, R. (2007). Unresolved maternal attachment representations, disrupted maternal behavior and disorganized attachment in infancy: Links to toddler behavior problems. Journal of Child Psychology and Psychiatry, 48(10), 1042-1050.

Marschak, M. (1960). A method for evaluating child-parent interaction under controlled conditions. The Journal of genetic psychology, 97(1), 3-22.

Mountain, G., Cahill, J., \& Thorpe, H. (2017). Sensitivity and attachment interventions in early childhood: A systematic review and meta-analysis. Infant Behavior and Development, 46, 14-32.

Munns, E. (Ed.). (2000). Theraplay®: Innovations in attachment-enhancing play therapy. Jason Aronson, Incorporated.

Mäntymaa, M., Puura, K., Luoma, I., Latva, R., Salmelin, R. K., \& Tamminen, T. (2015). Shared pleasure in early mother-infant interaction: predicting lower levels of emotional and behavioral problems in the child and protecting against the influence of parental psychopathology. Infant Mental Health Journal, 36(2), 223-237.

Odgers, C.L., Moffitt, T.E., Caspi, A., Broadbent, J.M., Dickson, N.P., Hancox, R., et al. (2008). Female and male antisocial trajectories: from childhood origins to adult outcomes. Development and Psychopathology, 20, 673-716 
Olfson, M., Blanco, C., Wang, S., Laje, G., \& Correll, C. U. (2014). National trends in the mental health care of children, adolescents, and adults by office-based physicians. JAMA Psychiatry, 71(1), 81-90.

Pajulo, M., Suchman, N., Kalland, M., \& Mayes, L. (2006). Enhancing the effectiveness of residential treatment for substance abusing pregnant and parenting women: Focus on maternal reflective functioning and mother-child relationship. Infant Mental Health Journal: Official Publication of The World Association for Infant Mental Health, 27(5), 448-465.

Pajulo, M., Pyykkönen, N., Kalland, M., Sinkkonen, J., Helenius, H., Punamäki, R. L., \& Suchman, N. (2012). Substance-abusing mothers in residential treatment with their babies: importance of pre- and postnatal maternal reflective functioning. Infant Mental Health Journal, 33, 70-81.

Patalay, P., Moulton, V., Goodman, A., \& Ploubidis, G. B. (2017). Cross-domain symptom development typologies and their antecedents: results from the UK millennium cohort study. Journal of the American Academy of Child \& Adolescent Psychiatry, 56(9), 765776.

Patterson, G. R. (2002). The early development of coercive family process. In J. B. Reid, G. R. Patterson, \& J. Snyder (Eds.), Antisocial behavior in children and adolescents: A developmental analysis and model for intervention (pp. 25-44)

Pearl, E., Thieken, L., Olafson, E., Boat, B., Connelly, L., Barnes, J., \& Putnam, F. (2012). Effectiveness of community dissemination of parent-child interaction therapy. Psychological Trauma: Theory, Research, Practice, and Policy, 4(2), 204.

Pinquart, M. (2017). Associations of parenting dimensions and styles with externalizing problems of children and adolescents: An updated meta-analysis. Developmental Psychology, 53(5), 873.

Polanczyk, G. V., Salum, G. A., Sugaya, L. S., Caye, A., \& Rohde, L. A. (2015). Annual Research Review: A meta-analysis of the worldwide prevalence of mental disorders in children and adolescents. Journal of Child Psychology and Psychiatry, 56(3), 345-365.

Powell, B., Cooper, G., Hoffman, K., \& Marvin, B. (2013). The circle of security intervention: Enhancing attachment in early parent-child relationships. Guilford Publications. 
Quetsch, L. B., Wallace, N., Norman, M., Travers, R., \& McNeil, C. (2015). Parent-Child Interaction Therapy With Children With Disruptive Behavior Disorders. Handbook of Play Therapy, 343.

Salo, S., \& Booth, P. (2019). The handbook of the Marschak Interaction Method (MIM). The Theraplay® Institute, Chicago.

Salo, S., \& Mäkelä, J. (2006). The Dyadic Emotional Interaction Style Manual. Finnish Psychological Corporation, Helsinki.

Sanders, M.R., \& Turner, K.T.T. (2018). The importance of parenting influencing the lives of children. In: M. R Sanders \& A. Morawska (Eds). Handbook of Parenting and Child Development Across the Lifespan, pp. 3-27. Springer.

Siu, A. F. (2009). Theraplay® in the Chinese world: An intervention program for Hong Kong children with internalizing problems. International Journal of Play Therapy, 18(1), 1-15.

Siu, A. F. (2014). Effectiveness of Group Theraplay® on enhancing social skills among children with developmental disabilities. International Journal of Play Therapy, 23(4), 187.

Siu, A. F. (2017). Use of touch in Theraplay® with ADHD children in a school setting. In Touch in Child Counseling and Play Therapy, pp. 63-75. Routledge.

Shaw, D., Gilliom, M., Ingoldsby, E., \& Nagin, D.S. (2003). Trajectories leading to school-age conduct problems. Developmental Psychology, 39, 189-200.

Shelleby, E. C., \& Shaw, D. S. (2014). Outcomes of parenting interventions for child conduct problems: A review of differential effectiveness. Child Psychiatry \& Human Development, 45(5), 628-645.

Slade, A. (2005). Parental reflective functioning: An introduction. Attachment \& human development, 7(3), 269-281.

Slade, A., Bernbach, E., Grienenberger, J., Levy, D., \& Locker, A. (2005). Addendum to Reflective Functioning scoring manual for use with the Parent Development Interview. Unpublished manuscript. City University of New York.

Sourander, A., \& Piha, J. (1997). Parent, teacher, and clinical ratings on admission to child psychiatric inpatient treatment: a study of cross-informant correlations using the CBCL, Rutter scales, and the CGAS. Nordic Journal of Psychiatry, 51(5), 365-370.

Steele, H., \& Steele, M. (Eds.). (2017). Handbook of attachment-based interventions. Guilford Publications. 
Stevens, S., \& Holcombe, J. (2015). Effect of Massage Therapy on Emotional Regulation Skills of Children With or at Risk for Disabilities (Doctoral dissertation, The College of St. Scholastica).

Suchman, N. E., DeCoste, C., Castiglioni, N., McMahon, T. J., Rounsaville, B., \& Mayes, L. (2010a). The Mothers and Toddlers Program, an attachment-based parenting intervention for substance using women: Post-treatment results from a randomized clinical pilot. Attachment \& Human Development, 12(5), 483-504.

Suchman, N. E., DeCoste, C., Leigh, D., \& Borelli, J. (2010b). Reflective functioning in mothers with drug use disorders: Implications for dyadic interactions with infants and toddlers. Attachment \& Human Development, 12, 567-585.

Suchman, N. E., DeCoste, C. L., McMahon, T. J., Dalton, R., Mayes, L. C., \& Borelli, J. (2017). Mothering From the Inside Out: Results of a second randomized clinical trial testing a mentalization-based intervention for mothers in addiction treatment. Development and Psychopathology, 29(2), 617-636.

Talen, M. (2000). Using Theraplay® in primary health care centers: A model for pediatric care. E. Munns (Ed). Theraplay: Innovations in attachment-enhancing play therapy, 339361.

Tully, L. A., \& Hunt, C. (2016). Brief parenting interventions for children at risk of externalizing behavior problems: A systematic review. Journal of Child and Family Studies, 25(3), 705-719.

Vuorenmaa, M. (2019). Pienten lasten ja heidän perheidensä hyvinvoint (Well-being of uoung children and their families). THL, National Institute for Health and Welfare, Finland.

Wang, F., Christ, S. L., Mills-Koonce, W. R., Garrett-Peters, P., \& Cox, M. J. (2013). Association between maternal sensitivity and externalizing behavior from preschool to preadolescence. Journal of Applied Developmental Psychology, 34(2), 89-100.

Wettig, H. H., Coleman, A., \& Geider, F. J. (2011). Evaluating the effectiveness of Theraplay® in treating shy, socially withdrawn children. International Journal of Play Therapy, 20(1), 26.

Zeanah, C. H., Berlin, L. J., \& Boris, N. W. (2011). Practitioner review: Clinical applications of attachment theory and research for infants and young children. Journal of Child Psychology and Psychiatry, 52(8), 819-833. 
Yap, M. B. H., \& Jorm, A. F. (2015). Parental factors associated with childhood anxiety, depression, and internalizing problems: A systematic review and meta-analysis. Journal of Affective Disorders, 175, 424-440.

Yap, M. B., Morgan, A. J., Cairns, K., Jorm, A. F., Hetrick, S. E., \& Merry, S. (2016). Parents in prevention: a meta-analysis of randomized controlled trials of parenting interventions to prevent internalizing problems in children from birth to age 18. Clinical Psychology Review, 50, 138-158. 
